\title{
ARBORIZAÇÃO DOS BAIRROS PINHEIROS, BRASÍLIA E BANCÁRIOS EM PATO BRANCO/PR
}

\author{
PLANTING IN THE PINHEIROS'S, BANCARIOS'S AND BRASILIA'S \\ QUARTERS IN PATO BRANCO/PR
}

\author{
Lenir Maristela SILVA ${ }^{1}$ \\ Denielly Arruda RODIGHIERO² \\ lonete $\mathrm{HASSE}^{3}$ \\ Danielle Acco CADORIN ${ }^{4}$
}

\begin{abstract}
RESUMO
Uma das questões que eleva a qualidade de vida nas cidades é a proporção de árvores implantadas. O objetivo deste estudo é apresentar os resultados de um inventário realizado nos bairros Bancários, Brasília e Pinheiros em Pato Branco/PR. Os dados coletados foram: identificação da espécie; altura do indivíduo; altura da primeira bifurcação; condições das raízes em relação ás calçadas; presença ou não de fiação elétrica; e a dimensão da área livre. A área inventariada apresenta a predominância de Ligustrum lucidum (42\%) e Lagerstroemia indica (19\%) e também uma baixa diversidade de espécies nos bairros Bancários e Brasília, enquanto que no bairro Pinheiros observou-se maior diversidade. Há falta de identidade arbórea nos três bairros, tanto no que se refere ao planejamento da paisagem de cada rua, quanto à presença de espécies nativas. Os resultados demonstram o predomínio de espécies $(59 \%)$ e indivíduos $(81,3 \%)$ exóticos nos três bairros. Encontram-se na lista das espécies exóticas invasoras no estado do Paraná 13,6\% das espécies. Dentre os conflitos entre a arborização e a área viária destaca-se o predomínio de pequena área livre e o fato da maioria das primeiras bifurcações ser inferior a $1,80 \mathrm{~m}$

Palavras-chave: arborização de vias públicas; inventário; Ligustrum.
\end{abstract}

\begin{abstract}
One of the questions that raise the quality of life in the cities is the ratio of implanted trees. The objective of this study is to present the results of an inventory carried through in Bancarios's, Brasilia's and Pinheiros's quarters of Pato Branco city - PR. The collected data had been: identification of the species; height of the specimen; height of the first bifurcation; conditions of the roots in relation to the sidewalk; presence or not of electric wiring; and the dimension of the free area. The inventoried area presents the predominance of the species Ligustrum lucidum (42\%) and Lagerstroemia indica (19\%) and also low diversity of species in the Bancarios's and Brasilia's quarters, while that in the Pinheiros's quarter a bigger diversity was observed. It has lack of arboreal identity in the three quarters, as much as for the planning of the landscape of each street and the presence of native species. The results demonstrate the predominance of exotic species (59\%) and specimens $(81,3 \%)$. Was in the list of the invading exotic species in the state of the Parana $13,6 \%$ of the species. Between the conflicts of arborization and road area, it is distinguished the predominance of small free area and the fact of the majority of the first bifurcations were situated lower than 1,80 m heigh.
\end{abstract}

Key-words: tree planting on public roads; inventory; Ligustrum.

\footnotetext{
Bióloga, Doutora em Produção Vegetal/UFPR. Professora da UTFPR, Via do Conhecimento, km 01, 85.503-390 - Pato Branco/PR, lenir@utfpr.edu.br (autora para correspondência);

${ }^{2}$ Acadêmica de Iniciação Científica do Curso de Agronomia/UTFPR;

${ }^{3}$ Bióloga, Doutora em Produção Vegetal/UFPR, Professora da UTFPR;

${ }^{4}$ Acadêmica de Iniciação Científica do Curso de Agronomia/UTFPR
} 


\section{INTRODUÇÃO}

Mais de $80 \%$ da população brasileira habita nas cidades (IBGE, 2000), portanto, áreas verdes nos centros urbanos são extremamente relevantes, tanto no que se refere à qualidade de vida, quanto aos atrativos turísticos e à conservação da biodiversidade. $O$ maior contato das pessoas com áreas verdes proporciona maior valorização desse bem por essas (BIONDI e ALTHAUS, 2005). O termo "áreas verdes urbanas" se aplica a diversos tipos de espaços, tanto em áreas públicas quanto privadas. Essas áreas podem ser representadas por paisagens não planejadas ou planejadas. As áreas verdes, geralmente, encontram-se em terrenos baldios, quintais de edificações, em praças, parques e nos passeios (DEMATTÊ, 1997).

A arborização de passeios (ou calçadas) é bastante complexa, pois as condições urbanas interferem muito no desenvolvimento das espécies. Uma avaliação de 1.243 árvores em ruas e parques de Oslo concluiu que as árvores de ruas possuíam saúde inferior às dos parques (FOSTAD e PEDERSEN, 1997).

No Brasil a produção científica na área de arborização urbana é muito incipiente. Ainda é muito restrita aos eventos científicos da área que tiveram início em 1985 com o I Encontro de Arborização Urbana na cidade de Porto Alegre. Além disso, de modo geral a arborização das cidades brasileiras não obedece a um planejamento anterior e por isso, decorrem vários problemas (GONÇALVES, et al. 2004).

Estudos que realizem um diagnóstico da arborização devem preceder qualquer planejamento desta (MILLER, 1997). Com o objetivo de contribuir com a Secretaria do Meio Ambiente no planejamento de suas ações, em 2005 iniciou-se um inventário acerca da arborização viária da cidade de Pato Branco/PR, que teve como primeiro foco o bairro Centro (SILVA et al., 2007). Dando prosseguimento a esses estudos nos anos de 2006 e 2007 foi analisada a arborização viária dos bairros Bancários, Brasília e Pinheiros, que juntos totalizam $14.806,22 \mathrm{~km}$ de área viária percorridos, sendo os resultados apresentados a seguir.

\section{MATERIAL E MÉTODOS}

A área urbana do município de Pato Branco, no sudoeste do Paraná - Brasil apresenta uma população de 56.739 (IBGE, 2000). O clima do município segundo Köppen é classificado de Cfa clima subtropical úmido mesotérmico (IAPAR, 2000). Destaca-se na região o solo do tipo Latossolo Vermelho Distroférrico (EMBRAPA, 1999). A região na qual o município se localiza foi anteriormente coberta por floresta do tipo Ombrófila Mista; composição do bioma Mata Atlântica. Tal região estende-se pelo segundo e terceiro planaltos do estado do Paraná e apresenta associações florísticas com a espécie Araucaria angustifolia (NETO, 2006).

O critério de escolha dos bairros analisados foi partir do bairro Centro (SILVA et al., 2007) estendendo-se para os bairros próximos e assim sucessivamente. Os três bairros aqui analisados localizam-se no entorno do bairro Centro. O bairro Brasília é o que apresenta maior área com 39,30 ha, seguido do bairro Pinheiros com 23,17 ha e do bairro Bancários com 21,29 ha.

Os dados foram coletados de 27 ruas dos três bairros com o auxílio de planilhas que continham além da identificação das espécies, os seguintes parâmetros relacionados a cada indivíduo adulto: altura $(\mathrm{m})$; altura da primeira bifurcação $(\mathrm{m})$; condições das raízes em relação ás calçadas (análise qualitativa); presença de danos nas calçadas; presença ou não de fiação elétrica; e dimensão da área livre (sem área livre; pequena área livre - inferior a $1 \mathrm{~m}^{2}$; boa área livre - igual ou acima de $1 \mathrm{~m}^{2}$. Foi utilizado um sistema de amostragem de quatro plantas da mesma espécie por rua para análise dos parâmetros supramencionados. Os demais indivíduos foram apenas identificados e quantificados. No caso de não ocorrência de quatro indivíduos da mesma espécie por rua, tomou-se as medidas do(s) indivíduo(s) existente(s) na rua. O período de coleta de dados foi de agosto de 2006 a março de 2007. As espécies foram registradas através de fotografias e também foram coletadas amostras férteis e herborizadas.

A freqüência (\%) das espécies foi calculada através da razão entre o número de indivíduos da espécie e o número total de indivíduos por bairro. Já as freqüências dos parâmetros arbóreos avaliados, foram calculadas através da razão entre o número de indivíduos amostrados da espécie e o número total de indivíduos amostrados por bairro.

\section{RESULTADOS E DISCUSSÃO}

Foram identificados 1.558 indivíduos adultos (Tabela 01). Nove indivíduos não puderam ser identificados devido à ausência de ramos férteis durante o período de coleta. Além disso, 405 indivíduos eram mudas e 64 estavam mortos devido a ocorrência de poda drástica. Com relação aos indivíduos adultos identificados, o bairro Bancários contava com 401 indivíduos, o bairro Brasília com 740 indivíduos e o bairro Pinheiros com 417 indivíduos.

Pode-se observar (Tabela 01) 66 espécies presentes nos bairros, sendo que a maior diversidade de espécies estava contida no bairro Pinheiros, com 47 espécies, seguido de Bancários com 37 e Brasília com 26. Das 66 espécies identificadas, 39 são exóticas e 27 são nativas do Brasil, destas últimas 13 são nativas da Floresta Ombrófila Mista. Já no que se refere à freqüência de indivíduos, 81,3\% são exóticos e 18,7\% são nativos do Brasil. Dos 1558 indivíduos adultos, 9,2\% são oriundos da Floresta Ombrófila Mista, região fitoecológica local. 
TABELA 01 - Número de indivíduos e freqüência das espécies presentes na arborização dos bairros Bancários, Brasília e Pinheiros de Pato Branco - PR/2006.

\begin{tabular}{|c|c|c|c|c|c|c|c|c|}
\hline $\begin{array}{l}\text { Nome } \\
\text { Vulgar }\end{array}$ & Nome Científico & Origem & & $\begin{array}{l}\text { cários } \\
\text { Freq. }\end{array}$ & & $\begin{array}{l}\text { asília } \\
\text { Freq. }\end{array}$ & & $\begin{array}{l}\text { neiros } \\
\text { Freq. }\end{array}$ \\
\hline Abacateiro & Persea americana Mill. & $E$ & -- & $0,00 \%$ & --- & $0,00 \%$ & 1 & $0,24 \%$ \\
\hline Acássia & $\begin{array}{c}\text { Acacia podalyriifolia Cunn. } \\
\text { Ex G. Don. }\end{array}$ & $E$ & --- & $0,00 \%$ & --- & $0,00 \%$ & 3 & $0,72 \%$ \\
\hline $\begin{array}{c}\text { Alámo } \\
\text { Prateado }\end{array}$ & Populus alba L. & $E$ & 2 & $0,50 \%$ & --- & $0,00 \%$ & -- & $0,00 \%$ \\
\hline Aleluia & $\begin{array}{l}\text { Senna multijuga (Rich.) } \\
\text { Irwin et. Barn }\end{array}$ & NB & 6 & $1,50 \%$ & --- & $0,00 \%$ & --- & $0,00 \%$ \\
\hline Ameixa & $\begin{array}{l}\text { Eriobotrya japonica } \\
\text { (Thunb.) Lindl. }\end{array}$ & $\mathrm{El}$ & 4 & $1,00 \%$ & 2 & $0,27 \%$ & --- & $0,00 \%$ \\
\hline Amora & Morus nigra L. & El & --- & $0,00 \%$ & --- & $0,00 \%$ & 3 & $0,72 \%$ \\
\hline Angico & $\begin{array}{c}\text { Anadenanthera falcata } \\
\text { (Benth.) Brenan }\end{array}$ & NB & 2 & $0,50 \%$ & --- & $0,00 \%$ & 4 & $0,96 \%$ \\
\hline Araçá & $\begin{array}{l}\text { Psidium cattleianum } \\
\text { Sabine }\end{array}$ & NFO & 1 & $0,25 \%$ & 1 & $0,14 \%$ & 2 & $0,48 \%$ \\
\hline Ariticum & $\begin{array}{c}\text { Rollinia silvatica (St. Hil.) } \\
\text { Mart. }\end{array}$ & NFO & --- & $0,00 \%$ & 1 & $0,14 \%$ & --- & $0,00 \%$ \\
\hline $\begin{array}{l}\text { Aroeira } \\
\text { Mansa }\end{array}$ & Schinus molle L. & NFO & 32 & $7,98 \%$ & 27 & $3,65 \%$ & 24 & $5,76 \%$ \\
\hline $\begin{array}{c}\text { Aroeira } \\
\text { Vermelha }\end{array}$ & $\begin{array}{c}\text { Schinus terebinthifolius } \\
\text { Raddi }\end{array}$ & NFO & -- & $0,00 \%$ & --- & $0,00 \%$ & 2 & $0,48 \%$ \\
\hline Caliandra & Calliandra brevipes Benth. & NB & --- & $0,00 \%$ & 2 & $0,27 \%$ & 4 & $0,96 \%$ \\
\hline Canafístula & $\begin{array}{l}\text { Peltophorum dubium } \\
\text { (Spreng.) Taub. }\end{array}$ & NB & 1 & $0,25 \%$ & --- & $0,00 \%$ & 2 & $0,48 \%$ \\
\hline Canela & $\begin{array}{c}\text { Ocotea porosa (Nees) L. } \\
\text { Barroso }\end{array}$ & NFO & -- & $0,00 \%$ & --- & $0,00 \%$ & 4 & $0,96 \%$ \\
\hline Caqui & Diospyros kaki L. F. & $E$ & 1 & $0,25 \%$ & --- & $0,00 \%$ & --- & $0,00 \%$ \\
\hline Cassia & Cassia fistula L. & $E$ & 1 & $0,25 \%$ & --- & $0,00 \%$ & --- & $0,00 \%$ \\
\hline Carvalho & Quercus robur L. & $E$ & -- & $0,00 \%$ & --- & $0,00 \%$ & 2 & $0,48 \%$ \\
\hline Cedro & Cedrela fissilis Vell. & NFO & -- & $0,00 \%$ & --- & $0,00 \%$ & 2 & $0,48 \%$ \\
\hline $\begin{array}{c}\text { Cereja do } \\
\text { Mato }\end{array}$ & Eugenia involucrata DC. & NFO & -- & $0,00 \%$ & --- & $0,00 \%$ & 6 & $1,44 \%$ \\
\hline Champaca & Michelia champaca L. & $E$ & 1 & $0,25 \%$ & --- & $0,00 \%$ & --- & $0,00 \%$ \\
\hline Chorão & Salix babylonica L. & $E$ & 1 & $0,25 \%$ & -- & $0,00 \%$ & --- & $0,00 \%$ \\
\hline Cinamomo & Melia azedarach L. & $\mathrm{El}$ & -- & $0,00 \%$ & 2 & $0,27 \%$ & 3 & $0,72 \%$ \\
\hline Cipreste & Cupressus spp. & $E$ & 1 & $0,25 \%$ & 1 & $0,14 \%$ & 10 & $2,40 \%$ \\
\hline Citrus & Citrus spp. & $E$ & 7 & $1,74 \%$ & 5 & $0,68 \%$ & 15 & $3,60 \%$ \\
\hline Dedaleiro & Lafoensia pacari St, Hil. & NFO & -- & $0,00 \%$ & 1 & $0,14 \%$ & 1 & $0,24 \%$ \\
\hline Erva Mate & Ilex paraguariensis St. Hil. & NFO & --- & $0,00 \%$ & --- & $0,00 \%$ & 4 & $0,96 \%$ \\
\hline $\begin{array}{l}\text { Escova de } \\
\text { Garrafa }\end{array}$ & $\begin{array}{l}\text { Callistemon speciosus } \\
\text { (Bonpl.) Sweet. }\end{array}$ & $E$ & 1 & $0,25 \%$ & --- & $0,00 \%$ & --- & $0,00 \%$ \\
\hline Espatódea & $\begin{array}{c}\text { Spathodea campanulata } \\
\text { P. Beauv. }\end{array}$ & $\mathrm{El}$ & --- & $0,00 \%$ & --- & $0,00 \%$ & 1 & $0,24 \%$ \\
\hline Eucalipto & Eucalyptus spp. ${ }^{4}$ & $E$ & $--\cdot$ & $0,00 \%$ & -- & $0,00 \%$ & 2 & $0,48 \%$ \\
\hline Extremosa & Lagerstroemia indica L. & $E$ & 87 & $21,70 \%$ & 135 & $18,23 \%$ & 63 & $15,11 \%$ \\
\hline $\begin{array}{l}\text { Falsa } \\
\text { Canela }\end{array}$ & $\begin{array}{c}\text { Cinnamomum zeylanicum } \\
\text { (Breyn.) Bl. }\end{array}$ & $E$ & --- & $0,00 \%$ & --- & $0,00 \%$ & 1 & $0,24 \%$ \\
\hline Ficus & Ficus sp. & $E$ & 6 & $1,50 \%$ & 4 & $0,53 \%$ & 10 & $2,40 \%$ \\
\hline Flamboyant & $\begin{array}{c}\text { Delonix regia (Bojer ex } \\
\text { Hook.) Rafin. }\end{array}$ & $E$ & -- & $0,00 \%$ & 1 & $0,14 \%$ & 5 & $1,20 \%$ \\
\hline Goiaba & Psidium guajava L. & $\mathrm{El}$ & 3 & $0,75 \%$ & 1 & $0,14 \%$ & --- & $0,00 \%$ \\
\hline Grevílea & $\begin{array}{c}\text { Grevillea robusta A. Cunn. } \\
\text { Ex R. Br. }\end{array}$ & $E$ & 1 & $0,25 \%$ & 2 & $0,27 \%$ & 2 & $0,48 \%$ \\
\hline
\end{tabular}


SILVA, L. M. et al. Arborização dos bairros...

TABELA 01 - (CONTINUAÇÃO) Número de indivíduos e freqüência das espécies presentes na arborização dos bairros Bancários, Brasília e Pinheiros de Pato Branco - PR/2006.

\begin{tabular}{|c|c|c|c|c|c|c|c|c|}
\hline Guamirim & Myrcia spp. & NFO & 1 & $0,25 \%$ & 1 & $0,14 \%$ & --- & $0,00 \%$ \\
\hline Guabiroba & $\begin{array}{c}\text { Campomanesia } \\
\text { eugenioides (Cambess.) } \\
\text { D. Legrand }\end{array}$ & NFO & 1 & $0,25 \%$ & --- & $0,00 \%$ & --- & $0,00 \%$ \\
\hline Hibisco & Hibiscus sinensis L. & $E$ & -- & $0,00 \%$ & --- & $0,00 \%$ & 4 & $0,96 \%$ \\
\hline Ipê Amarelo & $\begin{array}{c}\text { Tabebuia alba (Cham.) } \\
\text { Sandw. }\end{array}$ & NB & --- & $0,00 \%$ & --- & $0,00 \%$ & 53 & $12,71 \%$ \\
\hline $\begin{array}{l}\text { Ipê Amarelo } \\
\text { Miúdo }\end{array}$ & $\begin{array}{l}\text { Tabebuia chrysotricha } \\
\text { (Mart. ex. DC.) Standl. }\end{array}$ & NB & 5 & $1,25 \%$ & 3 & $0,41 \%$ & 12 & $2,88 \%$ \\
\hline Ipê Roxo & $\begin{array}{l}\text { Tabebuia heptaphylla } \\
\text { (Vell.) Tol. }\end{array}$ & NB & 6 & $1,50 \%$ & 4 & $0,53 \%$ & 3 & $0,72 \%$ \\
\hline Jacarandá & Jacaranda spp. & $E$ & 1 & $0,25 \%$ & --- & $0,00 \%$ & --- & $0,00 \%$ \\
\hline Ligustro & $\begin{array}{c}\text { Ligustrum lucidum W. T. } \\
\text { Aiton }^{4}\end{array}$ & El & 163 & $40,65 \%$ & 519 & $70,14 \%$ & 36 & $8,63 \%$ \\
\hline Liquidambar & Liquidambar styraciflua L. & $E$ & --- & $0,00 \%$ & --- & $0,00 \%$ & 1 & $0,24 \%$ \\
\hline Mamão & Carica papaya L. & $E$ & 1 & $0,25 \%$ & --- & $0,00 \%$ & --- & $0,00 \%$ \\
\hline $\begin{array}{l}\text { Manacá da } \\
\text { Serra }\end{array}$ & $\begin{array}{l}\text { Tibouchina mutabilis } \\
\text { Cong. }\end{array}$ & NB & --- & $0,00 \%$ & 1 & $0,14 \%$ & 2 & $0,48 \%$ \\
\hline Manduírana & $\begin{array}{l}\text { Senna macranthera } \\
\text { (Collad.) Irwin et. Barn }\end{array}$ & NB & 2 & $0,50 \%$ & --- & $0,00 \%$ & 19 & $4,56 \%$ \\
\hline Manga & Mangifera indica L. & $E$ & --- & $0,00 \%$ & --- & $0,00 \%$ & 1 & $0,24 \%$ \\
\hline Noz Pecan & $\begin{array}{c}\text { Carya illinoensis (Wang.) } \\
\text { Koch }\end{array}$ & $E$ & 1 & $0,25 \%$ & --- & $0,00 \%$ & 2 & $0,48 \%$ \\
\hline Paineira & Chorisia speciosa St. Hil. & NB & --- & $0,00 \%$ & --- & $0,00 \%$ & 1 & $0,24 \%$ \\
\hline Palmeira & Euterpe oleracea Mart. & NB & -- & $0,00 \%$ & 1 & $0,14 \%$ & 1 & $0,24 \%$ \\
\hline $\begin{array}{l}\text { Pata de } \\
\text { Vaca }\end{array}$ & Bauhinia variegata $\mathrm{L}^{3}$ & $E$ & 9 & $2,23 \%$ & 11 & $1,49 \%$ & 16 & $3,84 \%$ \\
\hline Pau Incenso & $\begin{array}{c}\text { Pittosporum undulatum } \\
\text { Vent. }\end{array}$ & $\mathrm{El}$ & 4 & $1,00 \%$ & 2 & $0,27 \%$ & 6 & $1,44 \%$ \\
\hline Pêssego & $\begin{array}{c}\text { Prunus persica (L.) } \\
\text { Batsch }\end{array}$ & $E$ & --- & $0,00 \%$ & --- & $0,00 \%$ & 1 & $0,24 \%$ \\
\hline Pinus & Pinus elliotii Engelm. & $\mathrm{El}$ & 10 & $2,48 \%$ & --- & $0,00 \%$ & --- & $0,00 \%$ \\
\hline Pitanga & Eugenia uniflora L. & NFO & 5 & $1,25 \%$ & 2 & $0,27 \%$ & 17 & $4,08 \%$ \\
\hline Plátano & Platanus $x$ acerifolia & $E$ & --- & $0,00 \%$ & 1 & $0,14 \%$ & --- & $0,00 \%$ \\
\hline Quaresmeira & $\begin{array}{c}\text { Tibouchina granulosa } \\
\text { Cogn }^{2}\end{array}$ & NB & 2 & $0,50 \%$ & --- & $0,00 \%$ & --- & $0,00 \%$ \\
\hline Romã & Punica granatum L. & $E$ & --- & $0,00 \%$ & --- & $0,00 \%$ & 2 & $0,48 \%$ \\
\hline Sete Copas & Terminalia catappa L. & El & 1 & $0,25 \%$ & --- & $0,00 \%$ & --- & $0,00 \%$ \\
\hline Sibipiruna & $\begin{array}{c}\text { Caesalpinia } \\
\text { peltophoroides Benth. }\end{array}$ & NB & --- & $0,00 \%$ & --- & $0,00 \%$ & 11 & $2,64 \%$ \\
\hline Timbaúva & $\begin{array}{c}\text { Enterolobium } \\
\text { contortisiliquum (Vell.) } \\
\text { Morong. }\end{array}$ & NB & 3 & $0,75 \%$ & --- & $0,00 \%$ & 2 & $0,48 \%$ \\
\hline Tipuana & $\begin{array}{c}\text { Tipuana tipu (Benth.) } \\
\text { Kuntze } \\
\end{array}$ & $E$ & 26 & $6,47 \%$ & 8 & $1,07 \%$ & 37 & $8,87 \%$ \\
\hline Tuia & $\begin{array}{c}\text { Cupressus macrocarpa } \\
\text { Hartw. ex. Gord. }\end{array}$ & $E$ & 1 & $0,25 \%$ & 2 & $0,27 \%$ & 4 & $0,96 \%$ \\
\hline Uvaia & Eugenia pyriformis Camb. & NFO & 1 & $0,25 \%$ & --- & $0,00 \%$ & -- & $0,00 \%$ \\
\hline Yucca & Yucca spp. & $E$ & --- & $0,00 \%$ & --- & $0,00 \%$ & 10 & $2,40 \%$ \\
\hline \multicolumn{3}{|c|}{ TOTAL DE INDIVÍDUOS } & 401 & $100 \%$ & 740 & $100 \%$ & 417 & $100 \%$ \\
\hline
\end{tabular}

NFO - Nativa da Floresta Ombrófila Mista (ISERNHAGEN, et al. 2002).

NB -Nativa do Brasil (EMBRAPA, 2001; BACKES e IRGANG, 2002; LORENZI, 1992; LORENZI, 2002).

E - Exótica (EMBRAPA, 2001; BACKES e IRGANG, 2004).

El - Exótica invasora (IAP, 2007). 
Nas cidades brasileiras observa-se uma crescente substituição da flora nativa por plantas exóticas, alterando o ambiente natural que resta nos centros urbanos. Este procedimento uniformiza as paisagens e contribui para a redução da biodiversidade no meio urbano, dissociando-o da região fitoecológica onde se insere (MACHADO et al., 2006).

As ações de arborização poderiam contribuir com a recuperação do patrimônio de biodiversidade natural que foi dilapidado no processo de fundação e expansão das cidades (REIS et al., 2003), mas não é isso que se constata ao inventariar-se a arborização das cidades brasileiras, como é o caso de Pato Branco.

Agravamento maior ocorre quando algumas espécies exóticas introduzidas na arborização são invasoras biológicas. Das espécies exóticas identificadas nos bairros, 09 são consideradas invasoras da flora no estado do Paraná (IAP, 2007), sendo estas: Eriobotrya japonica, Morus nigra, Melia azedarach, Spathodea campanulata, Psidium guajava, Ligustrum lucidum, Pittosporum undulatum, Pinus ellioti, Terminalia catappa.

Segundo a Convenção Internacional de Diversidade Biológica realizada em 2006, espécies exóticas são aquelas que ocorrem fora de sua área de distribuição natural e espécies exóticas invasoras são as que ameaçam ecossistemas, habitats ou outras espécies (ZILLER et al., 2007). Espécies exóticas invasoras constituem a segunda causa mundial de perda de biodiversidade, perdendo apenas para a conversão direta de ambientes e equiparando-se em grau de impacto às mudanças climáticas globais (IUCN, 2000).

Fragmentos de vegetação nativa existentes em parques e em áreas urbanas de grandes cidades podem abrigar uma expressiva riqueza de espécies. Contudo, muitas vezes, encontram-se isolados na paisagem, sem nenhuma garantia de que as espécies nativas e as funções e interações ecológicas do ecossistema permaneçam em condições necessárias para se manterem. Criar corredores de vegetação nativa por meio da arborização urbana, visando dar conectividade a estes fragmentos, pode ser uma estratégia conservacionista extremamente interessante no ambiente urbano (ZILLER et al., 2007).

Um outro problema identificado foi com relação à freqüência das espécies, pois evidenciouse a predominância da extremosa (Lagerstroemia indica) e do ligustro (Ligustrum lucidum) no conjunto dos bairros (19\% e 39\%, respectivamente). Considerando os bairros em separado, observa-se (Tabela 01) maior proporção de ligustro primeiramente no Bairro Brasília $(88,3 \%)$, em segundo lugar no bairro Bancários (62,3\%), enquanto que no Bairro Pinheiros tal proporção não chegou à casa dos $10 \%$. Estudos realizados no bairro Centro de Pato Branco identificaram na composição arbórea $62,4 \%$ de indivíduos dessa espécie (SILVA et al., 2007). Isso caracteriza outra problemática na arborização de Pato Branco, pois é recomendada uma freqüência máxima de 10 a 15\% de indivíduos de dada espécie na arborização das cidades (BIONDI e ALTHAUS, 2005). Uma das justificativas para tais valores seria a prevenção de um possível declínio de determinada espécie devido ao ataque de pragas e doenças (MILANO e DALCIN, 2000).

O bairro Pinheiros apesar de apresentar grande diversidade de espécies não possui um planejamento paisagístico. Percebe-se que a arborização foi criada por iniciativas particulares, pois a diversidade de espécies não contribui para trazer identidade, ou seja, para dar uma coerência paisagística visual ao bairro. O plantio aleatório prejudica o paisagismo, já que dilui o efeito estético dos atributos arbóreos. Esse procedimento é muito comum nas cidades brasileiras (SILVA-FILHO e BORTOLETO, 2005). O ideal é que haja diversidade, mas também que se respeite um determinado padrão de plantios, seja por quadra, ou seja, por rua (PIVETTA e SILVA FILHO, 2002; BIONDI e ALTHAUS, 2005). Em bairros de Nova Iguaçu/RJ esse problema de diversidade arbórea não planejada também é evidenciado (ROCHA et al., 2004).

Apesar de trazer inúmeros benefícios, a arborização viária também integra conflitos, já que como os demais componentes do ambiente urbano, disputa espaço físico e recursos para sua manutenção (COELBA, 2002). No inventário realizado, não foram identificados muitos danos causados pelas árvores. Nos bairros Bancários, Brasília e Pinheiros, respectivamente, foram encontradas freqüências de $37,9 \%, 28,5 \%$ e $14,2 \%$ com danos às calçadas. Pode-se comparar tais números aos encontrados no inventário do bairro Centro cuja freqüência desses danos variou entre $23 \%$ e $85 \%$ (MOCCELLIN et al., 2006). Contudo, nessa comparação deve-se levar em consideração que o bairro Centro de Pato Branco é o mais antigo da cidade e, conseqüentemente, suas árvores são mais velhas.

Grande parte dos danos causados por elementos arbóreos à pavimentação é provocada por uma escolha indevida da espécie e por falta de área livre adequada ao desenvolvimento da espécie. Dos $10,6 \%$ do total de indivíduos presentes na arborização nos três bairros analisados, 12 espécies estavam causando danos às calçadas, sendo essas: Persea americana; Anadananthera falcata; Ocotea porosa; Cedrela fissilis; Michelia champaca; Eucalyptus spp.; Grevillea robusta; Jacaranda spp.; Liquidambar styraciflua; Carya illinoensis; Chorisia speciosa; Pinus elliotii.

Espécies de grande porte são, geralmente, inadequadas para a arborização de passeios, pois apresentam arquitetura incompatível com as condições impostas pela pavimentação e redes subterrâneas existentes frequentemente nas áreas urbanas (SANTOS e TEIXEIRA, 2001; ANDRADE, 2002). O manejo das raízes de indivíduos arbóreos é complexo, pois além de problemas com o custo operacional desse trabalho, pode acarretar 0 desequilíbrio do vegetal em termos fisiológicos e causar, inclusive, quedas (ANDRADE, 2002). 
Outro aspecto relacionado com danos de calçadas pelas raízes das árvores é a falta de área livre adequada. Área livre é o espaço livre de pavimento que permitirá a infiltração da água e nutrientes e o mínimo recomendado para tal é de 1 $\mathrm{m}^{2}$ (SANTOS e TEIXEIRA, 2001). Nos três bairros constatou-se área livre pequena associada à maioria dos indivíduos (Tabela 02). No bairro Centro de Pato Branco também foi contabilizado alta freqüência de pequena área livre, 78\% das árvores apresentaram pouca ou nenhuma área livre (MOCCELLIN et al., 2006). Contudo, não houve uma proporção alta de calçadas com danos nos três bairros investigados, embora isso possa ser decorrente do estádio de desenvolvimento das espécies, pois a maioria não chegou ao pleno desenvolvimento.

TABELA 02 - Condição da área livre dos indivíduos avaliados na arborização dos bairros Bancários, Brasília e Pinheiros, Pato Branco - PR/ 2006.

\begin{tabular}{cccc}
\hline Área Livre & Bancários & Brasília & Pinheiros \\
\hline Sem área & $15,13 \%$ & $13,24 \%$ & $8,55 \%$ \\
Área pequena (inferior a $\left.1 \mathrm{~m}^{2}\right)$ & $43,86 \%$ & $60,30 \%$ & $11,93 \%$ \\
Boa área (igual ou superior a $1 \mathrm{~m}^{2}$ ) & $41,01 \%$ & $26,46 \%$ & $79,52 \%$ \\
\hline
\end{tabular}

Além de problemas com espécies inadequadas para uso em calçadas no sentido de causar danos as mesmas, outro fator que deve ser levado em conta no plantio de uma árvore em via pública é a arquitetura da copa. Árvores colunares devem ser evitadas, pois dificultam o trânsito de pedestres e têm como principal característica a ramificação monopodial, o que impossibilita qualquer tipo de intervenção (poda), que acabará deformando a arquitetura da copa (SANTOS e TEIXEIRA, 2001). No presente inventário, as espécies Cupressus spp., Callistemon speciosus, Eucalyptus spp., Grevillea robusta, Euterpe oleraceae, Pinus elliotii, Cupressus macrocarpa e Yucca spp. apresentam copa colunar, e, portanto, não deveriam estar implantadas em passeios.

Nos bairros Bancários, Brasília e Pinheiros, respectivamente, $50,8 \%, 58 \%$ e $57,9 \%$ das árvores encontravam-se sob a rede elétrica convencional. Nesses casos, a altura dos indivíduos variou entre $1 \mathrm{~m}$ e $23 \mathrm{~m}$. Os fios de alta tensão apresentam uma variação de $9 \mathrm{~m}$ a $12 \mathrm{~m}$ de altura (CEMIG, 2001).
Nos casos em que as espécies ultrapassam em altura esses limites, as podas são inevitáveis na cidade de Pato Branco. Uma alternativa para evitar possíveis conflitos provenientes da interação entre árvores e redes de energia elétrica, seria o uso de redes compactas (MENEGHETTI, 2003).

Nos três bairros analisados pode-se constatar que no geral as árvores apresentavam problemas quanto à posição da primeira bifurcação, pois em $68,6 \%$ a $81,9 \%$ dos casos os indivíduos apresentavam a primeira bifurcação inferior a 1,80 m (Tabela 03). A utilização de mudas com tamanho inferior a $1,80 \mathrm{~m}$ pode gerar problemas relativos à acessibilidade dos pedestres nos passeios. Para a implantação das mudas é necessário que as plantas tenham uma altura mínima de 1,80 m, livre de ramos o que garantirá que a primeira bifurcação da árvore, quando adulta, não esteja localizada abaixo desse limite, permitindo a livre circulação de pedestres (SANTOS e TEIXEIRA, 2001; COELBA, 2002; ELETROPAULO, 2006).

TABELA 03 - Altura da primeira bifurcação das espécies arbóreas nos bairros Bancários, Brasília e Pinheiros de Pato Branco - PR/2006.

\begin{tabular}{cccc}
\hline \multirow{2}{*}{ Altura da primeira bifurcação } & \multicolumn{3}{c}{ Freqüência por bairro (\%) } \\
\cline { 2 - 4 } & Bancários & Brasília & Pinheiros \\
\hline$<1,80 \mathrm{~m}$ & 68,66 & 75,04 & 81,93 \\
$=1,80 \mathrm{~m}$ & 7,32 & 4,62 & 3,67 \\
$>1,80 \mathrm{~m}$ & 24,02 & 20,35 & 14,40 \\
\hline TOTAL & 100 & 100 & 100 \\
\hline
\end{tabular}

\section{CONCLUSÕES}

A arborização dos bairros Bancários, Pinheiros e Brasília de Pato Branco/PR não contribu com a conservação do patrimônio da biodiversidade local, pois apresenta uma freqüência de $81,3 \%$ de indivíduos arbóreos exóticos. Uma das espécies exóticas mais abundantes é o ligustro (Ligustrum lucidum), com $39 \%$ de indivíduos. Essa espécie é invasora da Floresta Ombrófila Mista, região fitoecológica local. Além disso, o excesso de indivíduos exóticos faz com que os bairros não tenham identidade.

Nos três bairros há falta de planejamento paisagístico gerando vários conflitos entre a arborização e a área viária como pequena área livre disponível para o desenvolvimento das árvores e ocorrência da primeira bifurcação inferior a 1,80 m. 


\section{REFERÊNCIAS}

1. ANDRADE, T. O. Inventário e análise da arborização viária da estância turística de Campos do Jordão, SP. 112 f. Dissertação (Mestrado em Agronomia) - Escola Superior de Agricultura, Universidade Estadual de São Paulo, Piracicaba, 2002.

2. BACKES, P.; IRGANG, B. Árvores cultivadas no sul do Brasil: guia de identificação e interesse paisagístico das principais espécies exóticas. Porto Alegre: Palotti, 2004.

3. BACKES, P.; IRGANG, B. Árvores do Sul: Guia de identificação e interesse ecológico. Santa Cruz do Sul: Instituto Souza Cruz, 2002.

4. BIONDI, D.; ALTHAUS, M. Árvores de rua de Curitiba: cultivo e manejo. Curitiba: FUPEF, 2005.

5. CEMIG - Companhia de Energia Elétrica de Minas Gerais. Manual de arborização. Belo Horizonte: CEMIG, 2001.

6. COELBA - Companhia de Eletricidade do Estado da Bahia: Diretoria da Gestão de Ativos - Departamento de Planejamento dos Investimentos - Unidade de Meio Ambiente. Guia de arborização urbana. Salvador: Venturie Gráfica e Editora, 2002.

7. DEMATTÊ, M. E. S. P. Princípios de paisagismo. Jaboticabal: Funep. 1997.

8. ELETROPAULO - AES ELETROPAULO. Guia de arborização urbana. 2006. Disponível em: <http:// www.eletropaulo.com.br/portal/download.cfm?pasta_id=230>. Acesso em: 06/06/2007.

9. EMBRAPA - EMPRESA BRASILEIRA DE PESQUISA AGROPECUÁRIA - Centro Nacional de Pesquisa de Solos. Sistema Brasileiro de Classificação de Solos. Brasília: EMBRAPA, 1999.

10. EMBRAPA - EMPRESA BRASILEIRA DE PESQUISA AGROPECUÁRIA. Lista das espécies - Arboretos - Construindo Ecossistemas. 2001. Disponível em <http://www.arboretos.cnpm.embrapa.br/arboreto/lista.html> Acesso em 24/07/ 2006.

11. FOSTAD, O.; PEDERSEN, P. A. Vitality, variation and causes of decline of trees in Oslo Center (Norway). Journal of arboriculture. v. 23, n. 4, p 155-165, 1997.

12. GONCCALVES, E. O.; PAIVA. A. N.; GONÇALVES, W.; JACOVINE, L. A. G. Avaliação qualitativa de mudas destinadas à arborização urbana no estado de Minas Gerais. Revista Árvore, v. 28, n. 4, p. 479-486, 2004.

13. IAP - Instituto Ambiental do Paraná. Lista Oficial de Espécies Exóticas Invasoras para o Estado do Paraná. 2007. Disponível em: <www.iap.pr.gov.br/arquivos/File/iap/port_95_07.pdf>. Acesso em: 02/07/07.

14. IAPAR - INSTITUTO AGRONÔMICO DO PARANÁ. Cartas climáticas do Paraná. Londrina: IAPAR, 2000. 1 CD-ROM.

15. IBGE - Instituto Brasileiro de Geografia e Estatística. IBGE - Censos Demográficos. 2000. Disponível em: <www.ibge.gov.br/home/estatistica/populacao/default_censo_2000.shtm>. Acesso em: 10/04/2007.

16. ISERNHAGEN, I; SILVA, S. M.; GALVÃO, F. Listagem de espécies arbustivo-arbóreas citadas nos trabalhos de fitossociologia florestal no Paraná, Brasil: uma contribuição aos programas de recuperação de áreas degradadas (RAD). In: IPEF INSTITUTO DE PESQUISA E ESTUDOS FLORESTAIS A fitossociologia florestal no Paraná e os programas de recuperação de áreas degradadas: uma avaliação. 2002; Piracicaba: Instituto de Pesquisas e Estudos Florestais. v. 1, p. 51-134.

17. IUCN - INTERNATIONAL UNION FOR CONSERVATION OF NATURE. IUCN Guidelines for the prevention of biodiversity loss caused by alien invasive species. 51 st Meeting of Council, February, 2000.

18. LORENZI, H. Árvores Brasileiras: manual de identificação e cultivo de plantas arbóreas nativas do Brasil. Nova Odessa/SP: Plantarum, 1992.

19. LORENZI, H. Árvores Brasileiras: manual de identificação e cultivo de plantas arbóreas nativas do Brasil. Vol II. 2 ed. Nova Odessa: Plantarum, 2002.

20. MACHADO, R. R. B.; MEUNIER, I. M. J.; SILVA, A. J. A.; CASTRO, A. A. J. F. Árvores nativas para a arborização de Teresina, Piauí. Revista da Sociedade Brasileira de Arborização Urbana, v. 1, n. 1, p. 10-18, 2006.

21. MENEGHETTI, G. I. P. Estudo de dois métodos de amostragem para inventário da arborização de ruas dos bairros da orla marítima do município de Santos, SP. 115 f. Dissertação (Mestrado em Recursos Florestais) Escola Superior de Agricultura "Luiz de Queiroz", Universidade de São Paulo, Piracicaba, 2003.

22. MILANO, S.; DALCIN, E. Arborização de vias públicas. Rio de Janeiro: Light, 2000.

23. MILLER, R. W. Urban Forestry: planning and managing urban green spaces. 2 ed. New Jersey: Prentice Hall, 1997.

24. MOCCELLIN, R.; SILVA, L. M.; WEISSHEIMER, D. I.; ZBORALSKI, A. R.; FONSECA, L. Situação da arborização do centro da cidade de Pato Branco - PR. In: SEMINÁRIO DE INICIAÇÃO CIENTIFICA E TECNOLÓGICA, 9., 2006, Universidade Tecnológica Federal do Paraná, Curitiba. Anais... Curitiba: UTFPR, 2006. 1 CD-ROM.

25. NETO, J.D.C. Floresta Ombrófila Mista. 2006. Disponível em: <http://pt.wikipedia.org/wiki/ Floresta_ombr\%C3\%B3fila_mista>. Acesso em: 10/04/2007.

26. PIVETTA, K. F. L.; FILHO, D. F. S. Arborização Urbana - Boletim Acadêmico: Série Arborização Urbana. Jaboticabal: UNESP/FCAV/FUNEP, 2002.

27. REIS, A; ANJOS, A.; LEISSA, A. P.; BECHARA, F. C. Critérios para a seleção de espécies na arborização urbana ecológica. Sellowia. v. 53, n. 55, p. 51-67, 2003.

28. ROCHA, R. T.; LELES, P. S. S.; OLIVEIRA NETO, S. N. de. Arborização de vias públicas em Nova Iguaçu, RJ: o caso dos bairros Rancho Novo e Centro. Revista Árvore, v. 28, n. 4, p. 599-607, 2004.

29. SANTOS, N. R. Z. dos; TEIXEIRA, I. F. Arborização de vias públicas: ambiente x vegetação. Porto Alegre: Palotti, 2001.

30. SILVA-FILHO, D. F.; BORTOLETO, S. Uso de indicadores de diversidade na definição de plano de manejo de arborização viária de águas de São Pedro - SP. Revista Árvore, v. 29, n. 6, p. 973-982, 2005. 
SILVA, L. M. et al. Arborização dos bairros...

31. SILVA, L. M.; HASSE, I.; MOCELIN, R.; ZBORALSKI, A. Arborização de vias públicas e a utilização de espécies exóticas: o caso do bairro Centro de Pato Branco/PR. Scientia Agraria, v.8, n.2, p. 47-53 2007.

32. ZILLER, S. R.; ZENNI, R. D.; DECHOUM, M. de S. Espécies exóticas invasoras na arborização urbana: problemas e soluções. In: CONGRESSO BRASILEIRO DE ARBORIZAÇÃO URBANA, 11., 2007, Vitória/ES. Anais... Vitória: SBAU, 2007. 1 CD-ROM.

Recebido em 07/12/2007

Aceito em 04/06/2008 
